\title{
RNA Binding Protein LIN28B: a prime time player shaping neuroblastoma aggression and metastasis
}

\author{
Dongdong Chen ${ }^{1}$ and Robert W. Schnepp ${ }^{1,2}$ \\ ${ }^{1}$ Aflac Cancer and Blood Disorders Center, Department of Pediatrics, Emory University School of Medicine, Children's \\ Healthcare of Atlanta, Atlanta, GA, USA \\ ${ }^{2}$ Winship Cancer Institute, Emory University School of Medicine, Atlanta, GA, USA
}

Correspondence to: Robert W. Schnepp, email: robert.schnepp@emory.edu

Keywords: LIN28B; let-7; PBK; neuroblastoma; metastasis; RNA binding protein

Received: May 14, 2020

Accepted: May 17, 2020

Published: June 8, 2020

Copyright: @ 2020 Chen and Schnepp. This is an open-access article distributed under the terms of the Creative Commons Attribution License 3.0 (CC BY 3.0), which permits unrestricted use, distribution, and reproduction in any medium, provided the original author and source are credited.

Neuroblastoma, a pediatric cancer of the developing neural crest, is a strikingly heterogeneous disease, with clinical presentations ranging from the child with an asymptomatic abdominal mass to the patient presenting in extremis due to respiratory compromise [1]. At diagnosis, patients with high-risk disease generally have a primary (often abdominal) mass, as well as metastases in various sites, including the liver, bone marrow, cortical bone, and lymph nodes. Conceptually, most studies have focused on defining the biology and deregulated oncogenic signaling that promote growth of the primary tumor. In comparison, the mechanistic and molecular underpinnings of metastatic disease are less thoroughly explored.

Seeking to define novel drivers of neuroblastoma aggression, we utilized genome-wide association studies to identify an association between neuroblastoma susceptibility and germline variation in Lin-28 Homolog B (LIN28B) [2]. LIN28B is an RNA binding protein and one of its major functions is the inhibition of the maturation of the let-7 family of microRNAs [3, 4]. In addition, LIN28B binds directly to multiple RNA species, including mRNAs and non-coding RNAs $[5,6,7]$. In the physiological context, LIN28B promotes self-renewal, with let-7 opposing its effects [3]. In the oncogenic context, LIN28B is overexpressed in multiple adult and pediatric malignancies, including leukemias [8], colon $[7,9]$ and pancreatic cancer [10], neuroblastoma [2, 1113], and Wilms tumor [14]. Moreover, tissue-specific overexpression of LIN28B in mouse models leads to the development of various cancers, cementing its role as an oncogenic driver.

In neuroblastoma, we initially showed that high LIN28B expression is correlated with higher stage neuroblastoma and suboptimal outcome [2]. Subsequently, we demonstrated that LIN28B promotes the proliferation of neuroblastoma cells and defined RAN GTPase and Aurora kinase A (AURKA) as novel genes regulated by LIN28 [12]. As LIN28B has been shown to promote metastasis in two adult epithelial malignancies, esophageal [15] and colon cancer [9], we speculated that it might also influence neuroblastoma metastasis. In a murine xenograft model of neuroblastoma metastasis, we demonstrated that LIN28B indeed promotes metastasis [16]. Further, we showed that it drives metastasis by increasing both self-renewal and migration; in contrast, let-7 opposes these processes.

Next, we sought to define downstream targets of LIN28B, focusing our efforts on novel genes that are therapeutically tractable. We found the expression of LIN28B and PDZ binding kinase (PBK) expression to be strongly and positively correlated in tumors and focused our efforts on characterizing this interaction. PBK, also known as T-LAK cell-originated protein kinase (TOPK), is a serine/threonine kinase that promotes the self-renewal of neural stem cells; it is overexpressed in diverse adult histotypes and implicated in multiple hallmarks of cancer, including cell cycle regulation, apoptosis, and metastasis [17]. Our studies provided evidence that LIN28B promotes PBK expression and that PBK is both a LIN28B and a let-7 target (Figure 1A). We went on to additionally define PBK as a direct transcriptional target of MYCN, thus linking PBK to two neuroblastoma oncogenes, LIN28B and MYCN (Figure 1A). Finally, our studies illustrated that PBK promotes cell proliferation, selfrenewal, and migration, phenocopying LIN28B (Figure 1B).

These studies then reveal a novel role for LIN28B and PBK in shaping neuroblastoma metastasis. At the same time, they suggest a number of directions for future investigations into LIN28B-PBK signaling. While our findings show that PBK lies downstream of both LIN28B and MYCN, and the functions of PBK mimic those of LIN28B in vitro, whether PBK sculpts neuroblastoma metastasis in the in vivo setting is unknown. Given the 
overlap between LIN28B and PBK in mediating selfrenewal and migration, we hypothesize that both LIN28B and PBK promote neuroblastoma metastasis (Figure 1B). While our data support a role for LIN28B and PBK in cell proliferation, self-renewal, and migration, there are many additional steps in metastasis, including intravasation, dissemination, and extravasation, and it is reasonable to speculate that LIN28B and PBK may support these functions. While LIN28B remains a challenging target, PBK is currently therapeutically tractable and clinically relevant inhibitors, primarily targeting the kinase activity of PBK, exist. In preclinical models of colon
[18] and ovarian cancer [19], PBK inhibition leads to decreased metastatic dissemination. Might targeting PBK pharmacologically, either as single-agent therapy or in combination with chemotherapy or other targeted agents, reduce metastatic burden?

Our current study, focused on LIN28B-PBK signaling, in conjunction with our previous discovery of a LIN28B-RAN-AURKA network, [12] highlights two kinases that are downstream LIN28B/let-7 targets in neuroblastoma. Interestingly, other investigators have identified a LIN28B-RAN-AURKA signaling axis in hepatoblastoma [20] and have defined Aurora kinase B

A
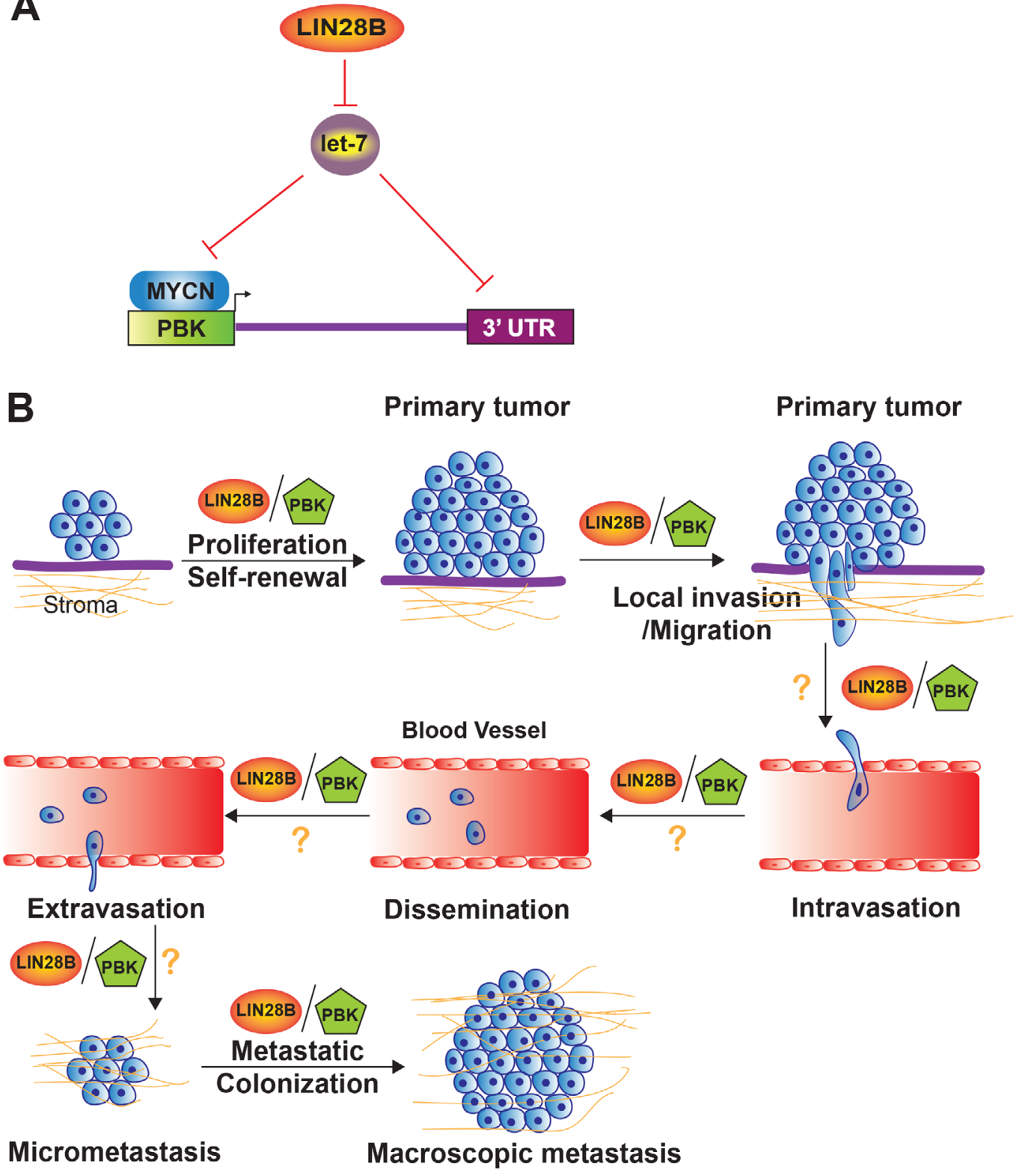

Figure 1: Model depicting the influence of LIN28B-PBK signaling on neuroblastoma metastasis. (A) A schematic diagram illustrates that two neuroblastoma oncogenes, LIN28B and MYCN, directly regulate the expression of PBK. LIN28B inhibits the maturation of the let-7 family of microRNAs, while let-7 binds the 3' UTR of PBK and inhibits the expression of PBK. MYCN directly binds to the PBK promoter, increasing transcription. (B) A schematic shows that LIN28B/PBK signaling promotes proliferation, self-renewal, and local invasion/migration. We speculate that LIN28B and PBK may be involved in additional steps of metastasis, as illustrated. Illustration is inspired by schematics depicted in Valastyan et al. [25] and Saxena et al. [26] 
(AURKB) as a molecular target of LIN28b/let-7 signaling [21]. Additionally, both LIN28A and B have been shown to regulate various components of the insulin-PI3KmTOR pathway, promoting glucose metabolism [22]. These various studies demonstrate that LIN28 influences multiple kinases and suggests the possibility that it may exert activity across the kinome. High-throughput profiling of the kinome will help identify the full repertoire of LIN28B-influenced kinases, furthering our understanding of how LIN28B influences this pivotal class of proteins. Given the therapeutic tractability of kinases, such approaches may nominate potential novel therapeutic vulnerabilities. With the involvement of LIN28B in metastatic dissemination, might subsets of these kinases help drive metastatic spread and could inhibiting such kinases diminish dissemination?

With respect to the molecular mechanisms by which LIN28B influences the oncogenic phenotype, it is clear that its influence on let-7 processing is pivotal. However, LIN28B has also been shown to bind to mRNAs and other RNA species directly. There are comprehensive studies that have utilized techniques such as ribonucleoprotein cross-linking, immunoprecipitation, and high-throughput sequencing (CLIP-Seq) to define direct LIN28B targets. However, many of these studies were performed in cell lines chosen for their robustness in cell culture as opposed to their faithful modeling of various tumor histotypes $[5,6]$. While these experiments have certainly yielded valuable insights, it will be of significant interest to utilize high-throughput technologies to identify LIN28Bbound mRNAs in the context of neuroblastoma and other histotypes. Ideally, such experiments would pair small RNA-Seq/RNA-Seq, CLIP-Seq/related technologies, and high-throughput proteomics approaches, allowing for the possibility of simultaneously studying the effects of LIN28B perturbation on the expression of mRNAs, RNA species, and protein.

Beyond the effects of LIN28B and let-7 on molecular signaling, there are significant discoveries to be made regarding the impact of LIN28B/let-7 on the metabolome, particularly in neuroblastoma and the other pediatric histotypes in which LIN28B has been implicated as an oncogenic driver. While elegant murine models have demonstrated the role of LIN28B/let-7 on fostering optimal glucose metabolism in the physiologic setting, our knowledge of how LIN28B/let-7 shapes metabolism in the oncogenic setting remains incomplete[22]. Future metabolomic profiling experiments in the context of neuroblastoma and other malignancies will help augment our knowledge of the roles of LIN28B in shaping the

\section{Future Directions}

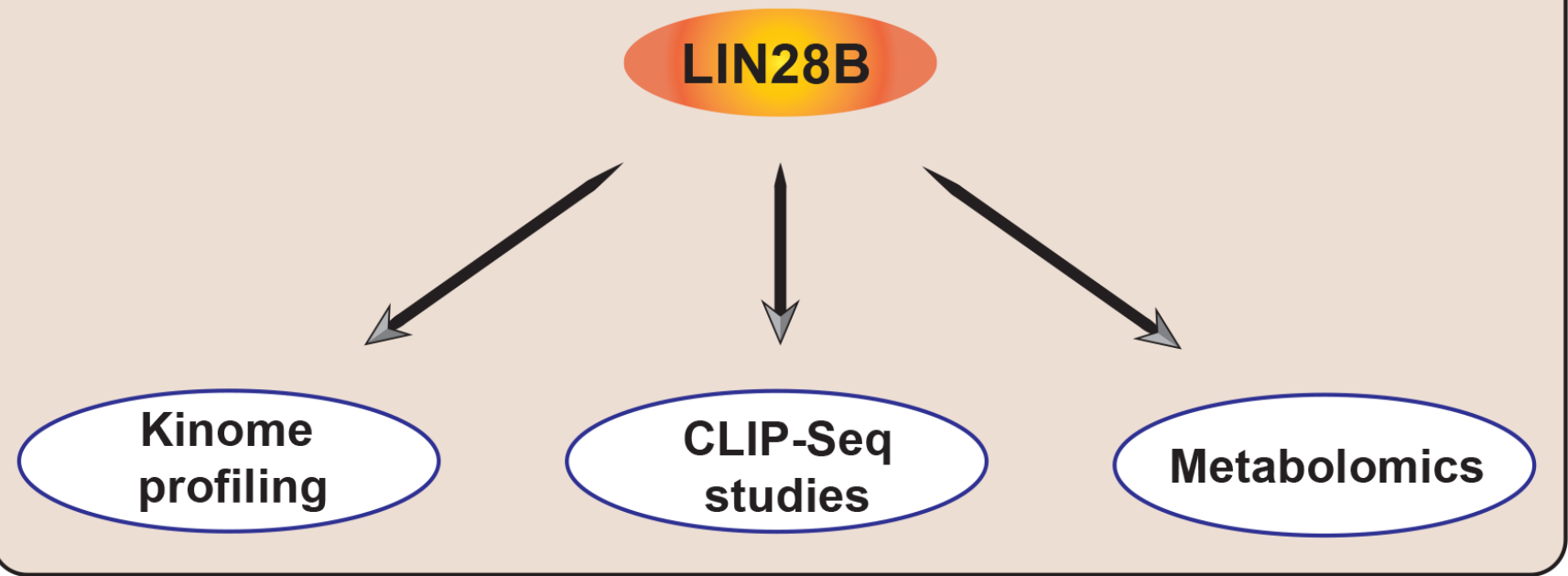

Figure 2: Future research directions to comprehensively define LIN28B functions. We propose high-throughput approaches, including kinome profiling and CLIP-Seq, to comprehensively identify LIN28B-influenced kinases and LIN28B- bound RNAs. Given the role of LIN28B in supporting glucose metabolism and the importance of metabolism in metastasis, metabolic profiling may help further our understanding of LIN28B function. 
malignant phenotype. Moreover, metastasizing cells must adjust their metabolisms to differing environments, ranging from escape from the primary tumor, to migration through the bloodstream and other tissues, to establishing outgrowth in new environments [23]. In this regard, experiments profiling the effects of LIN28B on the metabolic phenotype of neuroblastoma cells in differing phases of the metastatic process (i.e. growing as tumorspheres, during invasion/migration, initial outgrowth in metastatic lesion), would likely provide insights into not only LIN28 biology, but also further our understanding of neuroblastoma metastasis itself.

We have begun to develop a better understanding of how LIN28B shapes multiple hallmarks of the malignant phenotype, including cell proliferation, self-renewal, and metastasis. Additionally, we have outlined topics for further consideration, including how PBK affects metastasis, how LIN28B regulates the kinome, which targets are directly bound by LIN28B, and how LIN28B influences the metabolome (schematized in Figure 2). Taken together, such studies aim to clarify various cellular mechanisms by which LIN28B shapes neuroblastoma aggression. It is worth noting that, beyond LIN28B, there are approximately 1550 RNA binding proteins (RBPs) encoded in the human genome [24]. In addition to the research questions we have sketched out above, the potential contribution of these proteins to aggression in neuroblastoma and other tumors, is unknown, yet clearly of interest. We predict that such studies will nominate more "prime time" RBPs, providing a strong foundation for future efforts to drug this understudied class of proteins.

\section{CONFLICTS OF INTEREST}

The authors report no conflicts of interest.

\section{FUNDING}

This work was supported in part by NIH Grant K08-7K08CA194162-02, the Aflac Cancer and Blood Disorders Center Trust, and the William Woods, MD, Aflac Clinical Investigator Chair (R.W.S.).

\section{REFERENCES}

1. Matthay KK, Maris JM, Schleiermacher G, Nakagawara A, Mackall CL, Diller L, Weiss WA. Neuroblastoma. Nat Rev Dis Primers. 2016; 2:16078. https://doi.org/10.1038/ nrdp.2016.78. PMID:27830764

2. Diskin SJ, Capasso M, Schnepp RW, Cole KA, Attiyeh EF, Hou C, Diamond M, Carpenter EL, Winter C, Lee $\mathrm{H}$, Jagannathan J, Latorre V, Iolascon A, et al. Common variation at $6 \mathrm{q} 16$ within HACE1 and LIN28B influences susceptibility to neuroblastoma. Nat Genet. 2012; 44:112630. https://doi.org/10.1038/ng.2387. PMID:22941191

3. Shyh-Chang N, Daley GQ. Lin28: primal regulator of growth and metabolism in stem cells. Cell Stem Cell. 2013; 12:395-406. https://doi.org/10.1016/j.stem.2013.03.005. PMID:23561442

4. Schnepp RW, Diskin SJ. LIN28B: an orchestrator of oncogenic signaling in neuroblastoma. Cell Cycle. 2016; 15:772-74. https://doi.org/10.1080/15384101.2015.11377

\section{PMID:26743584}

5. Cho J, Chang H, Kwon SC, Kim B, Kim Y, Choe J, Ha M, Kim YK, Kim VN. LIN28A is a suppressor of ERassociated translation in embryonic stem cells. Cell. 2012; 151:765-77. https://doi.org/10.1016/j.cell.2012.10.019. PMID:23102813

6. Wilbert ML, Huelga SC, Kapeli K, Stark TJ, Liang TY, Chen SX, Yan BY, Nathanson JL, Hutt KR, Lovci MT, Kazan H, Vu AQ, Massirer KB, et al. LIN28 binds messenger RNAs at GGAGA motifs and regulates splicing factor abundance. Mol Cell. 2012; 48:195-206. https://doi. org/10.1016/j.molcel.2012.08.004. PMID:22959275

7. Madison BB, Liu Q, Zhong X, Hahn CM, Lin N, Emmett MJ, Stanger BZ, Lee JS, Rustgi AK. LIN28B promotes growth and tumorigenesis of the intestinal epithelium via Let-7. Genes Dev. 2013; 27:2233-45. https://doi. org/10.1101/gad.224659.113. PMID:24142874

8. Viswanathan SR, Powers JT, Einhorn W, Hoshida Y, Ng TL, Toffanin S, O'Sullivan M, Lu J, Phillips LA, Lockhart VL, Shah SP, Tanwar PS, Mermel CH, et al. Lin28 promotes transformation and is associated with advanced human malignancies. Nat Genet. 2009; 41:843-48. https:// doi.org/10.1038/ng.392. PMID:19483683

9. King CE, Cuatrecasas M, Castells A, Sepulveda AR, Lee JS, Rustgi AK. LIN28B promotes colon cancer progression and metastasis. Cancer Res. 2011; 71:4260-68. https://doi. org/10.1158/0008-5472.CAN-10-4637. PMID:21512136

10. Kugel S, Sebastián C, Fitamant J, Ross KN, Saha SK, Jain E, Gladden A, Arora KS, Kato Y, Rivera MN, Ramaswamy S, Sadreyev RI, Goren A, et al. SIRT6 Suppresses Pancreatic Cancer through Control of Lin28b. Cell. 2016; 165:1401-15. https://doi.org/10.1016/j.cell.2016.04.033. PMID:27180906

11. Molenaar JJ, Domingo-Fernández R, Ebus ME, Lindner S, Koster J, Drabek K, Mestdagh P, van Sluis P, Valentijn LJ, van Nes J, Broekmans M, Haneveld F, Volckmann R, et al. LIN28B induces neuroblastoma and enhances MYCN levels via let-7 suppression. Nat Genet. 2012; 44:1199-206. https://doi.org/10.1038/ng.2436. PMID:23042116

12. Schnepp RW, Khurana $\mathrm{P}$, Attiyeh EF, Raman $\mathrm{P}$, Chodosh SE, Oldridge DA, Gagliardi ME, Conkrite KL, Asgharzadeh S, Seeger RC, Madison BB, Rustgi AK, Maris JM, Diskin SJ. A LIN28B-RAN-AURKA Signaling Network Promotes Neuroblastoma Tumorigenesis. 
Cancer Cell. 2015; 28:599-609. https://doi.org/10.1016/j. ccell.2015.09.012. PMID:26481147

13. Powers JT, Tsanov KM, Pearson DS, Roels F, Spina CS, Ebright R, Seligson M, de Soysa Y, Cahan P, Theißen J, Tu HC, Han A, Kurek KC, et al. Multiple mechanisms disrupt the let-7 microRNA family in neuroblastoma. Nature. 2016; 535:246-51. https://doi.org/10.1038/nature18632. PMID:27383785

14. Urbach A, Yermalovich A, Zhang J, Spina CS, Zhu H, Perez-Atayde AR, Shukrun R, Charlton J, Sebire N, Mifsud W, Dekel B, Pritchard-Jones K, Daley GQ. Lin28 sustains early renal progenitors and induces Wilms tumor. Genes Dev. 2014; 28:971-82. https://doi.org/10.1101/ gad.237149.113. PMID:24732380

15. Hamano R, Miyata H, Yamasaki M, Sugimura K, Tanaka K, Kurokawa Y, Nakajima K, Takiguchi S, Fujiwara Y, Mori M, Doki Y. High expression of Lin28 is associated with tumour aggressiveness and poor prognosis of patients in oesophagus cancer. Br J Cancer. 2012; 106:1415-23. https://doi.org/10.1038/bjc.2012.90. PMID:22433967

16. Chen D, Cox J, Annam J, Weingart M, Essien G, Rathi KS, Rokita JL, Khurana P, Cuya SM, Bosse KR, Pilgrim A, Li D, Shields C, et al. LIN28B promotes neuroblastoma metastasis and regulates PDZ binding kinase. Neoplasia. 2020; 22:231-41. https://doi.org/10.1016/j. neo.2020.04.001. PMID:32339949

17. Herbert KJ, Ashton TM, Prevo R, Pirovano G, Higgins GS. T-LAK cell-originated protein kinase (TOPK): an emerging target for cancer-specific therapeutics. Cell Death Dis. 2018; 9:1089. https://doi.org/10.1038/s41419-018-1131-7. PMID:30356039

18. Kim DJ, Li Y, Reddy K, Lee MH, Kim MO, Cho YY, Lee SY, Kim JE, Bode AM, Dong Z. Novel TOPK inhibitor HI-TOPK-032 effectively suppresses colon cancer growth. Cancer Res. 2012; 72:3060-68. https://doi. org/10.1158/0008-5472.CAN-11-3851. PMID:22523035

19. Ikeda Y, Park JH, Miyamoto T, Takamatsu N, Kato T, Iwasa A, Okabe S, Imai Y, Fujiwara K, Nakamura Y, Hasegawa K. T-LAK Cell-Originated Protein Kinase (TOPK) as a Prognostic Factor and a Potential Therapeutic Target in Ovarian Cancer. Clin Cancer Res. 2016; 22:6110 17. https://doi.org/10.1158/1078-0432.CCR-16-0207. PMID:27334838

20. Zhang Y, Zhao Y, Wu J, Liangpunsakul S, Niu J, Wang L. MicroRNA-26-5p functions as a new inhibitor of hepatoblastoma by repressing lin-28 homolog B and aurora kinase a expression. Hepatol Commun. 2018; 2:861-71. https://doi.org/10.1002/hep4.1185. PMID:30027143

21. Liu P, Qi M, Ma C, Lao G, Liu Y, Liu Y, Liu Y. Let7a inhibits the growth of endometrial carcinoma cells by targeting Aurora-B. FEBS Lett. 2013; 587:2523-29. https:// doi.org/10.1016/j.febslet.2013.05.065. PMID:23769985

22. Zhu H, Shyh-Chang N, Segrè AV, Shinoda G, Shah SP,
Einhorn WS, Takeuchi A, Engreitz JM, Hagan JP, Kharas MG, Urbach A, Thornton JE, Triboulet R, et al, and DIAGRAM Consortium, and MAGIC Investigators. The Lin28/let-7 axis regulates glucose metabolism. Cell. 2011; 147:81-94. https://doi.org/10.1016/j.cell.2011.08.033. PMID:21962509

23. Lehuédé C, Dupuy F, Rabinovitch R, Jones RG, Siegel PM. Metabolic Plasticity as a Determinant of Tumor Growth and Metastasis. Cancer Res. 2016; 76:5201-08. https://doi. org/10.1158/0008-5472.CAN-16-0266. PMID:27587539

24. Gerstberger S, Hafner M, Tuschl T. A census of human RNA-binding proteins. Nat Rev Genet. 2014; 15:829-45. https://doi.org/10.1038/nrg3813. PMID:25365966

25. Valastyan S, Weinberg RA. Tumor metastasis: molecular insights and evolving paradigms. Cell. 2011; 147:275-92. https://doi.org/10.1016/j.cell.2011.09.024. PMID:22000009

26. Saxena M, Christofori G. Rebuilding cancer metastasis in the mouse. Mol Oncol. 2013; 7:283-96. https://doi. org/10.1016/j.molonc.2013.02.009. PMID:23474222 